\section{Mathematics Skills of Kosovar Primary
School Children: A Special View on Children \\ Mathematics Skills of Kosovar Primary
School Children: A Special View on Children with Mathematical Learning Difficulties*}

Linda Salihua ${ }^{a, * *}$, Pekka Räsänen ${ }^{\mathrm{b}}$

$\begin{array}{ll}\text { Received: } & \text { 03 January } 2018 \\ \text { Revised: } & 12 \text { February } 2018 \\ \text { Accepted: } & 21 \text { February } 2018 \\ \text { ISSN: } 1307-9298 \\ \text { Copyright @ IEJEE } \\ \text { www.iejee.com }\end{array}$

DOI: 10.26822/iejee.2018438132

\begin{abstract}
The present study examined the development of mathematics skills of Kosovar primary school children in terms of their gender, living area, socio-economic status, and achievement level. A special emphasis was placed on longitudinal investigations of the development of mathematics skills in children with learning difficulties in mathematics over a 2-year and 4-month period. Participants were 553 fourth-graders, 85 of whom identified with mathematical learning difficulties were classified into two subgroups: children with low mathematics achievement and children with limited mathematics ability. Results have shown that there were no gender differences in mathematics achievement. Children's living areas as well as their socio-economic status were observed to have a substantial impact on math performance. The performance level of limited math ability children was lower as compared to low math achieving children on all of the measures assessing math outcomes and reading comprehension. Findings indicate that a majority of the limited math ability group members still met the cutoff criterion after more than 2 years of school attendance.
\end{abstract}

Keywords: Mathematics skills assessment, mathematical learning difficulties, limited math ability, low math achievement, socio-economic background

\section{Introduction}

It is well recognized that many school-age children experience major difficulties in learning mathematics. Although having mathematical learning difficulties is not a new condition, only in recent years the research emphasis has been placed more seriously on this phenomenon by illuminating its complexity from varying perspectives, such as in terms of neuroscience; cognitive, developmental, and educational psychology; mathematics education; and special education. As a result of these efforts, a foundational pathway has been built for the establishment of a new discipline: mathematical learning difficulties (Siegler, 2007).

Traditionally, math ability has been considered more as a gift in a limited number of individuals, and society in general seems to have accepted this situation. Moreover, this acceptance shows in the reluctance and reservation of the majority to deal with mathematics as a universal language for all cultures, and the difficulties that occur while learning quantities and relations appear to be both expected and normal. This gives a plausible explanation for the persistence of math difficulties even into adulthood, impacting negatively on the individuals' decision-making in everyday life (McCloskey, 2007; Patton, Cronin, Bassett, \& Koppel, 1997; Curry, Schmitt, \& Waldron, 1996). Searching retrospectively, the roots of the failure in learning mathematics with understanding can be found in the first grades of primary school when mathematics as a subject begins to be formally taught. Thus, the importance of school-age children learning foundational math skills with insight during the first grades has become an immediate imperative, both in the mathematics curriculum and in terms of the instructional approach or pedagogy. A failure to learn the cornerstones of math, such as foundational math skills, may place children at potential risk for later educational and societal marginalization. In a developing country, as in Kosovo, with economic and social welfare deprivation, this is even more likely to happen. That is why the assessment of children's mathematics skills in school should become the first necessary, essential step for preventing such negative outcomes and supporting children's further development.

Research on normal mathematical development provides a useful framework for analyzing, understanding, assessing, and developing means for improving the performance of children with mathematical learning difficulties Jordan, Hanich, \& Uberti, 2003). Several studies on the normal development of mathematics skills have demonstrated empirically that most children, regardless of their socio-economic or cultural backgrounds, develop key elements of informal mathematics knowledge before they enter primary school and receive any formal mathematics education (Jordan, Huttenlocher, \& Levine, 1992; Jordan, Kaplan, \& Hanich, 2002; Jordan, Kaplan, Ramineni, \& Locuniak, 2009). It appears that the emergence of math ability in the early years is related to a child's overall cognitive development, which enables math skills to be acquired and developed gradually during the primary grades (Jordan, Levine, \& Huttenlocher, 1994). First, children learn to calculate by counting their fingers or concrete physical objects, and later they develop faster and more efficient counting strategies (Jordan et al., 2003). A combination of these two techniques allows them to balance speed and accuracy while they experience difficulties doing a task, which in turn increases the likelihood of them finding a correct solution (Jordan \& Montani, 1997). At this point, mathematical learning difficulties that emerge in children could be due to an inability to access mental representations of quantities when physical objects are not provided. As Jordan and colleagues

\footnotetext{
*This study is a part of Linda Salihu's doctoral dissertation (Department of Education, Special Education, University of Jyväskylä, Finland). ${ }^{a}, * *$ Corresponding author: Linda Salihu, Department of Pedagogy, Faculty of Education 350, University of Prishtina "Hasan Prishtina", Kosovo. E-mail: linda.salihu@uni-pr.edu

•Pekka Räsänen, Niilo Mäki Institute, 40014 University of Jyväskylä, Finland. E-mail: pekka.rasanen@nmi.fi
} 
(2003) have noted, at later stages of development, many primary school children might be competent in following rules and procedures, but they often follow the wrong ones. The authors (Jordan et al., 2003) stressed that memorizing a procedure without understanding its underlying principles can lead children to make consistent mistakes (e.g., adding instead of subtracting and vice versa, failing to borrow or carry, taking the smaller number away from the larger number regardless of its position, and so forth). Thus, it is obvious that internalizing and understanding math operations and principles require both of the fundamental prerequisites: conceptual and procedural knowledge (Gersten, Jordan, \& Flojo, 2005). In other words, a child should know not only what procedure to use and how to carry out that procedure, but also why he or she chose to do so.

Over the last two decades, several researchers have reported that mathematical learning difficulties are characterized either by developmental delays in the ability to apply calculation principles and strategies (Jordan \& Montani, 1997; Aunola, Leskinen, Lerkkanen, \& Nurmi, 2004), or by specific cognitive deficits (e.g., working memory, visual-spatial processing, or attention) in number fact retrieval and the execution of relevant procedures (Geary, 2004; Geary \& Hoard, 2001; Swanson \& Beebe-Frankenberger, 2004; Fuchs et al., 2005). As such, these shortcomings among children with mathematical learning difficulties may persist throughout primary school (Geary, 2004; Jordan, Hanich, \& Kaplan, 2003a, 2003b; Jordan et al., 2002; Hanich, Jordan, Kaplan, \& Dick, 2001; Ostad, 1998). Consequently, poor mastery of basic math skills further impedes the child's ability to focus on higher mathematical thinking (e.g., math word or story problems, algebra, geometry, etc.), as there are few or no cognitive resources left for recognizing and understanding the true meaning of the math task they are trying laboriously to perform. In addition, findings from previous research have shown that while the poor mathematics performance of primary school children was mediated by their weak number competence in kindergarten (Jordan et al., 2009; Jordan et al., 2003a), early understanding of number relations and operations provides support for learning complex calculation procedures involving thinking, reasoning and problem solving in varied contexts (Jordan et al., 2009; Booth \& Siegler, 2006; Rittle-Johnson, Siegler, \& Alibali, 2001; Geary, Hoard, Byrd-Craven, Nugent, \& Numtee, 2007). Studies also suggest that children's mathematical thinking should be assessed on tasks that are directly related to the teaching of mathematics in primary school Jordan et al., 2009; Jordan et al., 2003a; Rittle-Johnson et al., 2001; Baroody, 1996). This is because the nonverbal number and arithmetic concepts, as a basis for formal mathematical knowledge, seem to provide useful information about children's understandings of mathematics principles in terms of counting, arithmetic, place value, and so forth.

From this point of view, conducting such an assessment in Kosovo has been a challenge, since there has been no standardized assessment instruments for measuring children's mathematics skills and there has been a lack of domestic research documenting students' mathematics performance that would add to a cross-cultural perspective for understanding mathematical difficulties (Mullis, Martin, Foy, \& Arora, 2012; Sirin, 2005). The access to information provided by evidence-based research is of great importance and value for theoretical and practical purposes. To fill this gap, a Finnish test of math skills achievement for 9-12-year-olds (RMAT; Räsänen, 2004) has recently been translated and adapted to suit the Kosovo context. The main purpose of the RMAT is to identify children having difficulties with mathematics learning when placed under a time restriction for the completion of math tasks. Previous studies suggest that children with mathematical learning difficulties may perform as well as their typically achieving peers in untimed conditions (Jordan \& Montani, 1997; Geary, 1990). Therefore, as a time-limited test of basic math skills, RMAT seems suitable for the detection and identification of children encountering difficulties in learning mathematics. To understand the developmental nature of mathematical learning difficulties, follow-up assessments are necessary. Researchers pointed out that for the reliable determination of children's growth patterns, it is crucial that the measurement encompasses not only more than just a single assessment time point, but that this must be extended over two consecutive years, in which sustained difficulties in mathematics are more likely to unfold (see Geary, 1990; Mazzocco, 2007, for a complete discussion). This would also reduce the risk of false positives in identification (Mazzocco \& Myers, 2003). Despite these prerequisites, longitudinal studies are scarce and there is still a lack of consensus concerning the definition of mathematical learning difficulties (e.g., Jordan et al., 2002; Jordan et al., 2003a; Jordan et al., 2009; Mazzocco \& Myers, 2003; Geary, Hamson, \& Hoard, 2000; Geary et al., 2007; Geary, 2011; Geary, Hoard, Nugent, \& Bailey, 2012; Morgan, Farkas, \& Wu Qiong, 2009; Stock, Desoete, \& Roeyers, 2010; Vukovic \& Siegel, 2010), and thus our work was guided in that direction.

Additionally, the fact that all children are introduced to and familiarized with some aspects of basic math skills in their living environments long before they enter formal schooling also suggests the role of children's socio-economic backgrounds in this development, and thus, this needs to be considered when assessing their math skills. Several studies have acknowledged that more children from low socio-economic settings rather than those coming from middle socio-economic backgrounds meet the criteria for math difficulties (Royer \& Walles, 2007; Jordan \& Levine, 2009; Anders et al., 2012; Sirin, 2005; Davis-Kean, 2005; Jordan et al., 1994, 1992; Crane, 1996). With the publication of TIMSS 2011 International Results in Mathematics (Mullis et al., 2012), math results have been examined in the context of the major influences on student learning, including home support, school and learning climate, and teacher preparation for mathematics instruction, recognizing the complex interplay of societal, school, and home environmental factors. As the newest country in Europe, Kosovo has its specific context. It is worth to mention that Kosovo society has gone under the tremendous development during the last decades: from post-conflict and transitional struggle to effort for releasing from the troubled past and adjusting to a recent established democratic system. These positive and negative circumstances have directly influenced the students' and teachers' education in Kosovo as well.

Thus, our research efforts were focused on two key areas. First, the study aimed to examine mathematics skills development in fourth-grade children who have received formal mathematics education in primary school, taking into account their gender, living area, socio-economic status (SES), and achievement level. The reason for selecting fourth-graders for the study was based on the fact that most of the basic concepts and skills have been introduced to the children by that time in school, and because it is thought that mathematical learning difficulties may not be very stable in the earlier grades (Geary, 1990). As every child has his or her unique path in math skills development, it is assumed that this would reflect the differences even in the group of children identified with learning difficulties in mathematics. Thus, to assess the stability of the observed math problems, the study also focused on 
the development of math skills with a subgroup of children. The second aim was to examine the lowest performing subgroup of children with limited mathematics ability in comparison to the rest of the children with low mathematics achievement. The main research questions of the study were:

1. Whether mathematical performance of fourth-grade children is affected by (a) gender, (b) living area, and (c) socio-economic background?

2. Whether children with limited math ability differ from children with low math achievement in their mathematical development?

3. Whether performance on math skill measures accurately predicted group membership over time (stability and/ or change)?

\section{Method}

\section{Participants}

A total of 553 Kosovar fourth-grade children $(M=115$ months, $S D=5.58$ months) participated in the present study. Of these, 306 were boys and 247 were girls. The participating schools were randomly selected from five main regions of Kosovo. In each school, the children in two classes were tested. Altogether, 20 classes from 10 schools took part in the study. Within a subset of those classes, children with difficulties in learning mathematics were identified. Schools from urban and rural areas were included in this study so as to accurately represent the population. There were 314 children from urban areas and 239 children from rural areas.

Then, on the basis of poor performance on the RMAT mathematics achievement (a cutoff criterion at or below the $15^{\text {th }}$ percentile for limited math ability and a cutoff criterion above the $15^{\text {th }}$ percentile, but below the 35th percentile for low math achievement), a subsample of 85 children (48 boys and 37 girls) with learning difficulties in mathematics were selected from the main sample. They came from eight classes of two urban $(n=31)$ and two rural ( $n=54)$ primary schools selected randomly in two municipalities of Kosovo with middle to low SES. Children with poor mathematics skills were identified by the use of the mathematics achievement RMAT test (Räsänen, 2004; Räsänen \& Salihu, 2006). Based on the RMAT test score, all children who scored below the 35th percentile on national norms were included in the study. As suggested by prior research, there are two reasons for using this cutoff percentile. First, because it increases the possibility for picking up in the screening those children who have serious mathematical learning difficulties (Hanich et al., 2001; Jordan et al., 2003b; Geary et al., 2000; Jordan \& Montani, 1997; Räsänen \& Ahonen, 1995), and second, math achievement based on RMAT score may mask children's specific deficits because the test contains different types of items (see Mazzocco, 2007; Mazzocco \& Myers, 2003; Gersten et al., 2005; Gersten, Clarke, Haymond, \& Jordan, 2011, for a complete discussion). All children attended general education classes and none of them were receiving special educational services. During the follow-up, eight children moved to other schools and one, for personal reasons, discontinued participation in the study. All parents, except one, gave their written consent for participation in the study. As a result, 76 children (63 with low math achievement and 13 with limited math ability) were included in the analyses of the follow-up. Prior to its initiation, the study protocol was approved by the Kosovo Ministry of Education, Science and Technology Committee.

The children's background information that was related to their parents' occupations was collected from the school records. The data comprised of $95.3 \%$ for the fathers of the children and only $8.7 \%$ for the mothers of the children (mostly women-headed households). Specific data for the parents' educational level were not available. Based on occupational category, it was possible to distinguish each parent's occupation as belonging to one of the two categories: white-collar professions or blue-collar professions. A total of $27.1 \%$ of mothers and $20.5 \%$ of fathers were working in white-collar professions (such as doctors, attorneys, economists, engineers, teachers, etc.), and $16.7 \%$ of mothers and $69.1 \%$ of fathers were working in blue-collar professions (mostly part-time workers). In addition, $56.3 \%$ of mothers' and $10.4 \%$ of fathers' activities did not belong to either of the above-mentioned groups (e.g., housewives, students, pensioners, or unemployed).

\section{Measures}

Mathematics achievement. The children's mathematics achievement was assessed in a group classroom situation with RMAT - A Mathematical Achievement Test for 9-12-year-olds (Räsänen, 2004; Räsänen \& Salihu, 2006). The RMAT was used for all participants in this study to determine which children had mathematical learning difficulties and required additional support (Salihu, Aro, \& Räsänen, 2017). RMAT is a time-restricted group test enabling screening of many children in a short time. The RMAT test mainly consists of basic math skills, such as multi-digit calculations (e.g., $6000-627 ; 204 \cdot 12)$, fractions and decimals (e.g., 3/10; $5 \cdot 0.3$ ), measurement (e.g., $9 \mathrm{I}=\ldots \mathrm{dl}$ ), and algebra tasks (e.g., x: $20=8$ ). The original item selection for the RMAT was based on the idea of a restricted time for test completion to enable screening of many children in a short time. The test items were assessed first by conducting a pilot study with the Kosovo population. The Kosovo RMAT-test is a translation of the Finnish RMAT-test, and preliminary results showed that there was no need for major adaptation made to the items. This means that the original character of the Finnish RMAT-test items were not lost in the translation process. In Kosovo the test was used as a screening tool in order to identify children with mathematical difficulties a year and a half before the other data were collected. The time limit for the test was 10 minutes. Since RMAT was developed as a one-dimensional test (Räsänen, 2004), there is only one total score to interpret. One point is given for each correct answer. Consequently, the total maximum score for the test is 56 points. The reliability and validity of the RMAT test have been shown to be sufficiently high in Finnish population (Räsänen, 2004) and Swedish population of Finland (Räsänen, Linnanmäki, Haapamäki, \& Skagersten, 2008), and it has proven to be suitable for measuring mathematics skills of Kosovar children. As reported by Räsänen (2004), the Cronbach alpha reliability was .92-.95 at ages 9-12; the correlation with the WRAT-R (Jastak \& Wilkinson, 1984) was .547-.659. The Cronbach alpha coefficient on the Kosovo sample was .916. The RMAT test was used two more times with the group of children identified as having learning difficulties in mathematics with an interval of six months between the second and third assessments. The Cronbach alpha reliabilities on this sample at two measurement points were .892 and .912 .

\section{Calculation skills}

The Mathematics Performance Test on Calculations (MPT-C; Salihu, 2008) comprised of 25 items with oneand two-digit number combinations (addition, subtraction, multiplication, and division operations) and with four response options presented horizontally. It was 
administrated in a group classroom situation. Children had 20 minutes for task completion. The score was the number of correct answers. The Cronbach alpha reliability on this sample was .889 .

\section{Reading comprehension}

The children's reading comprehension was assessed by a short passage with five questions and four response options presented beneath in a worksheet. The test was given in a group situation. Children had 5 minutes to respond. The score was the number of correct responses. The task was used three times within a year with an interval of 5 months in between. The correlations between the summed scores at three measurement points ranged from .491 to .678 .

\section{Nonverbal intelligence}

Children's general IQ was assessed using the Raven's Standard Progressive Matrices (SPM) (1976) test. The SPM measures nonverbal reasoning with 60 items divided into five sets ( $A, B, C, D$, and $E)$, each made up of 12 problems which become progressively more difficult. The test was administered individually. The test administrator presented a series of patterns and the child selected the missing piece from 6 or 8 possible choices. The score is the number of correct responses. The test is considered to be an efficient instrument to measure cognitive ability of subjects from childhood until adulthood (Raven, Raven, \& Court, 1998).

\section{Procedure}

The data collection was carried out in the middle of the school year among fourth-grade primary school children (see Table 1) in five main regions of Kosovo. The RMAT test was administered in groups of 12-15 children in the classroom. It was administered by the first author, with the help of the class teacher. Pencils and eraser were the only permissible equipment for the test, but children were allowed to count with their fingers or use a piece of paper for their workings. The children were allowed to count with their fingers or use a piece of paper for their workings. The children were instructed to solve as many of the problems as they could within the 10-minute time limit. After receiving the test instructions, the children were given the RMAT test booklets.

Table1. Assessment Timeline During Three Consecutive School Years

\begin{tabular}{lll}
\hline Grade Fourth & Grade Fifth & Grade Sixth \\
\hline RMAT 1 & MPT-C & RMAT 2 \\
\cline { 2 - 3 } & $\begin{array}{l}\text { Reading } \\
\text { comprehension 1 }\end{array}$ & $\begin{array}{l}\text { Reading } \\
\text { comprehension 2 }\end{array}$ \\
\cline { 2 - 3 } & RPM & RMAT 3 \\
\cline { 2 - 3 } & & Reading \\
& comprehension 3 \\
\hline
\end{tabular}

Note. $R M A T=$ math achievement test, MPT- $C=$ math performance test on calcula tions, RPM= Raven's progressive matrices, 1, 2, 3= assessment time point.

After the first assessment, the group of children identified by the RMAT test as low achievers in mathematics was assessed further, over the 2-year and 4-month follow-up period. In addition, since our main sample was spread out across the territory of Kosovo, we were only able to include 85 children in the follow-up. The second assessment, at the end of fifth grade, consisted of a math performance (MPT-Calculation) test, a reading comprehension task, and Raven's SPMs. Further, the RMAT and reading comprehen- sion skills were assessed two more times at the beginning and in the middle of sixth grade (see Table 1).

\section{Data analysis}

Raw scores were used in the data analyses. All the analyses were performed at significance level .01. After checking the assumptions for parametric testing, univariate analyses of variance (ANOVAs) were carried out to examine the impact of gender, living area, and socio-economic background on children's mathematics skills. This allowed us to assess the main effects of gender, living area, and socio-economic background, as well as their possible interactions in the main sample and in the subsample.

Next, we examined the difference between children with low math achievement and children with limited math ability in terms of their performance on different scales using an ANOVA. The pattern of growth in children's math achievement was investigated using a repeated measures ANOVA. Finally, the percentages of changes in group membership were used to assess the stability of the classification over time.

\section{Results}

\section{Results for the main sample}

The results of the present study showed that the mean RMAT Kosovo score $(M=24.72, S D=7.59, n=553)$ was almost identical to that reported for the pilot sample ( $M=$ 24.03, $S D=7.45, n=67$ ).

ANOVAs revealed no statistically significant gender differences in children's math skills, $F(1,549)=4.43, p=.036$, $\eta^{2}=.008$ (see Table 2 ). A statistically significant difference in math performance was found between children from urban areas and those from rural areas, $F(1,549)=70.21$, $p<.001, \eta^{2}=.113$, the children from the rural areas scoring lower as compared to their peers from the urban areas (Table 2). The gender-by-living-area (urban, rural) interaction did not reach significance $(p=.128)$.

An ANOVA showed that parents' professional category also had a significant effect on children's achievement score, indicating that children whose parents were in white-collar professions had better scores in math as compared to those whose parents were in blue-collar or other occupations: for both parents, $F(2,550)=15.16$, $p<.001, \eta^{2}=.05$; for mothers, $F(2,45)=5.69, p=.006, \eta^{2}=$ .20 ; and for fathers, $F(2,524)=14.26, p<.001, \eta^{2}=.05$. No significant differences were found in the performance of children whose parents (mothers and fathers) belonged to blue-collar and other occupational categories (see Table 2). Tukey tests revealed that children whose parents were in white-collar professions achieved better scores than children whose parents were in blue-collar professions (mean difference $=4.30, S E=0.77$ ) and those whose parents were in the other occupational category (mean difference $=4.39$, $S E=1.05)$. However, no differences were observed in terms of achievement in RMAT between children whose parents belonged to blue-collar and other occupational categories (mean difference $=0.08, S E=0.89$ )

Overall, the omnibus result revealed that there was no significant interaction between parents' occupation and living area, $F(2,541)=1.29, p=.276$, or parents' occupation and gender, $F(2,541)=0.35, p=.705$. The interaction between gender and living area was also not significant, $F(1$, $541)=2.41, p=.121$. The same pattern was observed for 193 children identified with low achievement in mathematics (all $p>$.205). 
Table 2. Descriptive Information for Children's Math Skills Performance by Gender, Living Area, and Parental Occupation Category

\begin{tabular}{|c|c|c|c|c|c|c|c|c|c|c|c|c|c|c|c|}
\hline \multirow{2}{*}{$\begin{array}{c}\text { Parents } \\
\text { Professional } \\
\text { Category }\end{array}$} & \multicolumn{3}{|c|}{ All } & \multicolumn{3}{|c|}{ Girls } & \multicolumn{3}{|c|}{ Boys } & \multicolumn{3}{|c|}{ Urban } & \multicolumn{3}{|c|}{ Rural } \\
\hline & $n$ & $M$ & $s d$ & $n$ & $M$ & $s d$ & $n$ & $M$ & $s d$ & $n$ & $M$ & $s d$ & $n$ & $M$ & sd \\
\hline White collar & 112 & 28.21 & 5.97 & 49 & 27.73 & 6.36 & 63 & 28.59 & 5.67 & 89 & 28.76 & 5.75 & 23 & 26.09 & 6.44 \\
\hline Blue collar & 365 & 23.91 & 7.84 & 154 & 23.60 & 7.70 & 211 & 24.14 & 7.96 & 174 & 26.60 & 6.31 & 191 & 21.46 & 8.30 \\
\hline Other & 76 & 23.83 & 7.18 & 44 & 23.80 & 6.91 & 32 & 23.88 & 7.64 & 51 & 24.80 & 6.81 & 25 & 21.84 & 7.62 \\
\hline Total & 553 & 24.77 & 7.60 & 247 & 24.45 & 7.47 & 306 & 25.03 & 7.70 & 314 & 26.92 & 6.37 & 239 & 21.95 & 8.16 \\
\hline
\end{tabular}

Findings showed that these children do not differ in math performance as a function of gender $(p=.577)$, but they differ significantly as a function of living area, again with lower score for children from rural schools $F(1,189)=8.30$, $p=.004, \eta^{2}=.04$ (see Table 3).

Table 3. Descriptive Information for Low Mathematics Achievement Subgroup by Gender and Living Area

\begin{tabular}{rrrrrr}
\hline Variable & $n$ & Mean & SD & $F(1.189)$ & $p$ \\
\hline Girls & 86 & 16.21 & 6.14 & 0.31 & .577 \\
\cline { 1 - 4 } Boys & 107 & 16.67 & 5.76 & & \\
\hline Urban & 74 & 17.97 & 4.87 & 8.30 & .004 \\
\cline { 1 - 3 } Rural & 119 & 15.53 & 6.33 & & \\
\hline
\end{tabular}

Results for the subsample

The results from the analyses further revealed that with the exception of their IQ level, which did not differ significantly $(p>.100)$, children with limited math ability performed significantly worse than children with low math achievement on all the other measures (RMAT 1, RMAT 2, RMAT 3, Calculation, Reading comprehension 1, Reading comprehension 2, and Reading comprehension 3), with all $p<.010$ (see Table 4).

To investigate the pattern of growth in children's math skills and the changes that occur over time in more depth, a repeated measures ANOVA was undertaken with assessment (RMAT 1,2,3) as a within-subject factor, and subgroup (low achievement and limited ability) as a between-subject factor. The results showed that there was a significant improvement in children's math performance over the period of time, $F(2,146)=47.77, p<.001, \eta^{2}=.39$. The interaction between assessment and subgroup did not reach significance, $F(2,146)=0.26, p=.770$, revealing a similar pattern of development of math skills across the two groups. The same findings were observed for chil- dren's reading comprehension skills, with a significant main effect, $F(2,146)=8.05, p<.001, \eta^{2}=.10$, and no significant interaction effect between the factors, $F(2,146)=0.80$, $p=.453$. The significant main effect for the subgroup indicated that the difference in math performance remained across assessments between the groups, $F(1,73)=75.47$, $p<.001, \eta^{2}=.51$. A similar result was found for reading comprehension, $F(1,73)=19.94, p<.001, \eta^{2}=.21$.

The stability of the classification was determined by looking at the percentages of the changes in group membership over time. Based on the scores in RMAT, approximately $60 \%$ of the children ( 8 out of 13 children) were classified correctly into the limited math ability group, remaining consistently below the 15th percentile of the limited math ability criterion across three assessment points. Moreover, about $30 \%$ of the children still remained in the low math achievement group in the fifth and sixth grades, performing below the 35th percentile (as the cutoff criterion).

\section{Discussion}

This study was designed to examine the development of mathematics skills of Kosovar primary school children with respect to gender, living area, socio-economic status, and achievement level. A special emphasis was placed on, and thus increased attention was devoted to the longitudinal investigation of the development of mathematics skills in children with learning difficulties in mathematics over a 2-year and 4-month period.

The results of the study reveal that there are no significant differences in mathematics performance between boys and girls. This finding was expected, since it is in accordance with the most frequent findings from the other studies (Lachance \& Mazzocco, 2006; Lindberg, Hyde, Petersen, \& Linn, 2010; Royer \& Walles, 2006; Tate, 1997; Marshall \& Smith, 1987). Our findings expand upon previous studies and support the claim that gender differences

Table 4. Performance Outcomes in Mathematics Skills, Reading Comprehension, and Nonverbal Reasoning by Low Achievement Subgroups

\begin{tabular}{|c|c|c|c|c|c|c|}
\hline \multirow{2}{*}{ Variable } & \multicolumn{2}{|c|}{ Low Mathematics Acihievement } & \multicolumn{4}{|c|}{ Limited Mathematics Ability } \\
\hline & Mean & $S D$ & Mean & $S D$ & $F(1.74)$ & $p$ \\
\hline RMAT 1 & 18.16 & 3.74 & 6.08 & 2.60 & 22.62 & $<.001$ \\
\hline RMAT 2 & 25.54 & 5.50 & 13.46 & 5.14 & 53.10 & $<.001$ \\
\hline RMAT 3 & 25.50 & 7.45 & 14.62 & 5.14 & 25.12 & $<.001$ \\
\hline MPT-C & 16.32 & 5.18 & 7.38 & 4.07 & 34.20 & $<.001$ \\
\hline Reading comprehension 1 & 3.37 & 1.31 & 2.08 & 1.32 & 10.38 & .002 \\
\hline Reading comprehension 2 & 3.89 & 1.18 & 2.15 & 1.73 & 19.69 & $<.001$ \\
\hline Reading comprehension 3 & 4.15 & 1.13 & 2.77 & 1.74 & 13.03 & .001 \\
\hline RPM & 36.51 & 5.67 & 31.15 & 5.24 & 9.84 & .002 \\
\hline
\end{tabular}

Note. $R M A T=$ math achievement test, MPT-C= math performance test on calculations, $R P M=$ Raven's progressive matrices, 1, 2, 3= assessment time point. 
in mathematics achievement for children from the third to sixth grades are minimal or nonexistent (Mullis et al., 2012; Marshall \& Smith, 1987), and that girls and boys perform very similarly almost on all assessments of mathematics skills (Lachance \& Mazzocco, 2006; Tate, 1997; Lindberg et al., 2010).

In contrast, the study results demonstrate that there is a huge gap in math skills achievement between the children as a function of their living area, indicating that those who live in urban areas performed significantly better and achieved higher scores than their rural counterparts did. One of the explanatory factors for the mathematics achievement gap between urban and rural children is inequality in learning opportunities and support. In fact, children from rural areas of Kosovo have less access to educational opportunities both at home and in the classroom, which in turn has had a major impact on their mathematics knowledge and skills from early childhood onward. More specifically, rural children typically come from a lower socio-economic background, which is associated with having a lower parental-education level, lower income, and consequently, limited resources for obtaining adequate nutrition, and for having stimulating didactic materials in their homes, as well as not being able to afford enrichment activities (sport, music, dance). Almost all of these disadvantage factors are considered to be associated with lower academic performance (Crane, 1996; LeFevre et al., 2009; Davis-Kean, 2005; Dooley, 2011, McNamara \& Kendeou, 2011; Thornton, 2018). Consistent with this finding, Mullis and colleagues (Mullis et al., 2012) reported that a location of school (urban vs. rural) had a substantial impact on students' overall low mathematics achievement in the developing countries which are in close distance with Kosovo such as, Macedonia, Croatia, Romania, Turkey, etc. Moreover, findings from our study are in line with prior studies showing that children's math skills seem to be af fected by parental occupation category, favoring children whose parents are in white-collar professions (Mullis et al., 2012; Anders et al., 2012; Kaşkaya, Calp, \& Kuru, 2017; Si rin, 2005). As a result of the social and cultural variation in the children's home settings, it is likely that the input they receive may also vary qualitatively (Castro et al., 2015).

Indeed, since the children were fourth-graders, it might be quite plausible that the explanation for this disparity lies in inadequate and poor quality mathematics instruction, which is determined mostly by the teachers' insufficient educational background, qualification being achieved with only a 2-year associate's degree. The process of qualification of in-service teachers with a bachelor's degree has been finalized in the recent years. In line with this, Ertle, Ginsburg and colleagues (Ertle et al., 2008) also found that teachers of children with low SES tend to have lower levels of education and less teaching experience than teachers of children with middle SES, and the quality of math instruction is substantially related to the teachers' education and their professional development (Reid \& Reid, 2017).

When the group of low mathematics achievers was divided into two subgroups, we found substantial differences between low math achieving children and limited math ability children in terms of their performance in reading comprehension and nonverbal reasoning. Findings show that children with limited math ability performed much worse than children with low math achievement on all of the scales, including measures for the math outcomes. This suggests that children with limited ability may have more pervasive academic deficits than children with low achievement. Similar findings with regard to reading-related skills and IQ that highlighted potential qualitative differences in the two groups of children with mathematical learning difficulties have been reported in other studies (see Hanich et al., 2001; Mazzocco \& Myers, 2003; Jordan et al., 2003b; Murphy et al., 2007; Vukovic \& Siegel, 2010).

Regardless of group membership, development was observed in the children of both groups over the follow-up period. A comparison of children in the two groups also showed that while the low math achieving children reached the fourth-grade performance level in the sixth grade, the limited math ability children still lagged far behind. It should also be noted that the groups were similar with respect to gender, living area, SES, and nonverbal reasoning.

Although most children with mathematical learning difficulties exhibit difficulties with fluent, accurate, and automatic retrieval of basic arithmetic combinations, the findings support the claim that children with limited math ability represent a distinct subgroup in comparison to the group of children with low math achievement Jordan \& Montani, 1997; Jordan et al., 2003b; Geary et al., 2007; Geary et al., 2012). In comparison to low achieving children, the limited ability children performed substantially worse in all of the math-related skill tasks. As has been found (Geary et al., 2007; Murphy et al., 2007; Stock et al., 2010; Vukovic \& Siegel, 2010), while the use of a lenient criterion identifies children that may have more subtle deficits in a certain math domain, the use of a restrictive cutoff criterion identifies children with pervasive and often severe cognitive deficits as well as underlying deficits in working memory and processing speed.

The study showed that the confirmed status of children with limited math ability, since around $60 \%$ of them continually met the cutoff criterion below the 15 th percentile on three assessment points more than 2 years after the original classification. Our finding is consistent with the study showing that approximately $66 \%$ of children with limited math ability continue to meet this criterion over time (Mazzocco \& Räsänen, 2013). Taken together, although the data document the stability of mathematical difficulties that become a distinctive feature for limited math ability children over time, persistent mathematical difficulties were also observed in approximately $30 \%$ of children with low math achievement.

\section{Limitations}

It is worth noting, however, that the small number of children with limited math ability can be considered as a limitation of the study and should be taken into account in any attempts for generalizing the findings. In order to compensate for this, an adjusted alpha was used and effect sizes were provided which reveal the magnitude of differences for comparisons between groups. Furthermore, the measure we used for reading comprehension served as a brief control task for assessing children's reading comprehension and it is not a standardized one. To gain a deeper understanding of children reading ability perhaps a more sophisticated standardized measure for assessing reading fluency and comprehension is needed.

\section{Conclusions and Future Directions}

The findings of the present study suggest that mathematics instruction during the primary school grades in Kosovo is not at the level needed, since a considerable number of the fourth-grade children seem not to be educated adequately in mathematics. Thus, the major concern that arises here is not whether children are capable of learning mathematics skills (Ertle et al., 2008), but whether teachers are able to teach them to every individual child, includ- 
ing those with mathematical learning difficulties, by showing enough sensitivity toward children's unique learning needs. Seen from this perspective, it is not surprising that in Kosovo, as in most Balkan countries, students with learning difficulties are not rarely considered as a burden in the classroom. Although this attitude has started to change (Thomas. 2013), creating opportunities for equal access to knowledge and skills for all children, as it is stressed earlier, still remains a challenge for today's teachers and to teacher education (Tarrou, 1996; Darling-Hammond \& Baratz-Snowden, 2005; Hargreaves \& Fullan, 2012).

In regard to this, a special emphasis should be put on identification and prevention of early math failure in the first primary grades, particularly in rural schools, since as the results suggest, it can have persistent negative consequences for later math learning. Furthermore, the interventions programs tailored to meet the learning needs of children in two subgroups should become an integrative part of math teaching. Our study documented that children with low math achievement and children with limited math ability represent two distinctive subgroups since they differ not only in math performance, but also in reading comprehension, and nonverbal reasoning. Attendance of more than two years of regular math instruction in school did not change the status of majority of children identified with limited math ability. If left untreated with special educational service most of the children with limited math ability, as well as a considerable number of the children with low math achievement, will remain in the same subgroup over time.

As mathematics is by nature cumulative and progressive, and because it has been shown that early mathematics skills are even more powerful predictors of later school success than reading skills are (Duncan et al., 2007), it is of critical importance to detect and identify problems as early as possible. In fact, the challenge of tackling inadequate mathematics learning and instruction, as well as students' low achievement in mathematics, has become a matter of national concern in many countries (Gersten et al., 2009). Thus, further research is necessary to examine and determine the long-term effectiveness of instructional math interventions that provide opportunities for math learning to directly connect from the classroom to the home, and consequently, have the potential to help children with mathematical learning difficulties improve their mathematics competency.

\section{Acknowledgments}

This study was supported by the Finnish Support to the Development of Education in Kosovo (FSDEK II) Project and in part by the University of Prishtina "Hasan Prishtina". We wish to express our appreciation to the children for their generosity in sharing their time to participate in the study.

\section{References}

Anders, Y., Rossbach, H.-G., Weinert, S., Ebert, S., Kuger, S., Lehrl, S., \& von Maurice, J. (2012). Home and preschool learning environments and their relations to the development of early numeracy skills. Early Childhood Research Quarterly, 27(2), 231-244.

Aunola, K., Leskinen, E., Lerkkanen, M., \& Nurmi, J.-E. (2004). Developmental dynamics of math performance from preschool to grade 2. Journal of Educational Psychology, 96(4), 699-713.

Baroody, A. J. (1996). An investigative approach to teaching children labeled learning disabled. In D. K. Reid, W. P. Hresko, \& H. L. Swanson (Eds.), Cognitive approaches to learning disabilities (pp. 545-615). Austin, TX: Pro-Ed.

Booth, J. L., \& Siegler, R. S. (2006). Developmental and individual differences in pure numerical estimation. Developmental Psychology, 42(1), 189-201.

Castro, M., Exposito-Casas, E., Lopez-Martin, E., Lizasoain, L., Navarro-Asencio, E., \& Luis Gaviria, J. (2015). Parental involvement on student academic achievement: A meta-analysis. Educational Research Review, 14, 33-46.

Crane, J. (1996). Effects of home environment, SES, and maternal test scores on mathematics achievement. Journal of Educational Research, 89(5), 305314.

Curry, D., Schmitt, M. J., \& Waldron, S. (1996). A framework for adult numeracy standards: The mathematical skills and abilities adults need to be equipped for the future. Boston, MA: World Education.

Darling-Hammond, L., \& Baratz-Snowden, J. (Eds.) (2005). A good teacher in every classroom: Preparing the highly qualified teachers our children deserve. San Francisco: Jossey-Bass.

Davis-Kean, P. E. (2005). The influence of parent education and family income on child achievement: The indirect role of parental expectations and the home environment. Journal of Family Psychology, 19(2), 294-304.

Dooley, C. M. (2011). The emergence of comprehension: A decade of research 2000-2010. International Electronic Journal of Elementary Education, 4(1), 169-184.

Duncan, G. J., Dowsett, C. J., Claessens, A., Magnuson, K., Huston, A. C., Klebanov, P., Pagani, L., Feinstein, L., Engel, M., Brooks-Gunn, J., Sexton, H., Duckworth, K., \& Japel, C. (2007). School readiness and later achievement. Developmental Psychology, 43(6), 1428-1446.

Ertle, B. B., Ginsburg, H. P., Cordero, M. I., Curran, T. M., Manlapig, L., \& Morgenlander, M. (2008). The essence of early childhood mathematics education and the professional development needed to support it. In A. Dowker (Ed.), Mathematical difficulties: Psychology and intervention (pp. 59-83). Amsterdam: Elsevier.

Fuchs, L. S., Compton, D. L., Fuchs, D., Hollenbeck, K. N., Craddock, C. F., \& Hamlett, C. L. (2008). Dynamic assessment of algebraic learning in predicting third graders' development of mathematical problem solving. Journal of Educational Psychology, 100(4), 829-850.

Fuchs, L. S., Compton, D. L., Fuchs, D., Paulsen, K., Bryant, J. D., \& Hamlett, C. L. (2005). The prevention, identification, and cognitive determinants of math difficulty. Journal of Educational Psychology, 97(3), 493-513.

Geary, D. C., Hoard, M. K., Nugent, L., \& Bailey, D. H. (2012). Mathematical cognition deficits in children with learning disabilities and persistent low 
achievement: A five-year prospective study. Journal of Educational Psychology, 104(1), 206-223.

Geary, D. C. (2011). Cognitive predictors of achievement growth in mathematics: A five-year longitudinal study. Developmental Psychology, 47(6), 1539-1552.

Geary, D. C., Hoard, M. K., Byrd-Cravent, J., Nugent, L., \& Numtee, C. (2007). Cognitive mechanisms underlying achievement deficits in children with mathematical learning disability. Child Development, 78(4), 1343-1359.

Geary, D. C. (2004). Mathematics and learning disabilities. Journal of Learning Disabilities, 37(1), 4-15.

Geary, D. C., \& Hoard, M. K. (2001). Numerical and arithmetic deficits in learning-disabled children: Relation to dyscalculia and dyslexia. Aphasiology, 15(7), 635-647.

Geary, D. C., Hamson, C. O., \& Hoard, M. K. (2000). Numerical and arithmetical cognition: A longitudinal study of process and concept deficits in children with learning disability. Journal of Experimental Child Psychology, 77, 236-263.

Geary, D. C. (1990). A componential analysis of an early learning deficit in mathematics. Journal of Experimental Child Psychology, 49, 363-383.

Gersten, R., Jordan, N. C., \& Flojo, J. R. (2005). Early identification and interventions for students with mathematical difficulties. Journal of Learning Disabilities, 38(4), 293-304.

Gersten, R., Beckmann, S., Clarke, B., Foegen, A., Marsh, L., Star, J. R., \& Witzel, B. (2009). Assisting students struggling with mathematics: Response to intervention (Rtl) for elementary and middle schools (NCEE 2009-4060). Washington, DC: National Center for Education Evaluation and Regional Assistance, Institute of Education Sciences, U.S. Department of Education. Retrieved from https://ies.ed.gov/ncee/ wwc/Docs/PracticeGuide/rti_math_pg_042109.pdf

Gersten, R., Clarke, B. S., Haymond, K., \& Jordan, N. C. (2011). Screening for mathematics difficulties in $K-3$ students (2nd ed.). Portsmouth, NH: RMC Research Corporation, Center on Instruction. Retrieved from https://files.eric.ed.gov/fulltext/ED524577.pdf

Hanich, L. B., Jordan, N. C., Kaplan, D., \& Dick, J. (2001). Performance across different areas of mathematical cognition in children with learning difficulties. Journal of Educational Psychology, 93(3), 615-626.

Hargreaves, A., \& Fullan, M. (2012). Professional capital: Transforming teaching in every school. London and New York: Routledge.

Hill, H. C., Rowan, B., \& Ball, D. L. (2005). Effects of teacher mathematical knowledge for teaching on student achievement. American Educational Research Journal, 42(2), 371-406.

Jastak, S., \& Wilkinson, G. S. (1984). The wide range achievement test: Revised. Wilmington, DE: Jastak Associates.

Jordan, N. C., \& Levine, S. C. (2009). Socioeconomic variation, number competence, and mathematics learning difficulties in young children. Developmental Disabilities Research Reviews, 15(1), 60-68.

Jordan, N. C., Kaplan, D., Ramineni, C., \& Locuniak, M. N. (2009). Early math matters: Kindergarten number competence and later mathematics outcomes. Developmental Psychology, 45(3), 850-867.

Jordan, N. C., Hanich, L. B., \& Uberti, H. Z. (2003). Mathematical thinking and learning difficulties. In A. J. Baroody \& A. Dowker (Eds.), The development of arithmetic concepts and skills: Constructing adaptive expertise (pp. 359-383). Mahwah, NJ: Erlbaum.

Jordan, N. C., Hanich, L. B., \& Kaplan, D. (2003a). Arithmetic fact mastery in young children: A longitudinal investigation. Journal of Experimental Child Psychology, 85(2), 103-119.

Jordan, N. C., Hanich, L. B., \& Kaplan, D. (2003b). A longitudinal study of mathematical competencies in children with specific mathematics difficulties versus children with co-morbid mathematics and reading difficulties. Child Development, 74(3), 834-850.

Jordan, N. C., Kaplan, D., \& Hanich, L. B. (2002). Achievement growth in children with learning difficulties in mathematics: Findings of a two-year longitudinal study. Journal of Educational Psychology, 94(3), 586-597.

Jordan, N. C., \& Montani, T. O. (1997). Cognitive arithmetic and problem solving: A comparison of children with specific and general mathematics difficulties. Journal of Learning Disabilities, 30(6), 624-634.

Jordan, N. C., Levine, S. C., \& Huttenlocher, J. (1994). Development of calculation abilities in middle- and low-income children after formal instruction in school. Journal of Applied Developmental Psychology, 15(2), 223-240.

Jordan, N. C., Huttenlocher, J., \& Levine, S. C. (1992). Differential calculation abilities in young children from middle- and low-income families. Developmental Psychology, 28(4), 644-653.

Kaşkaya, A., Calp, Ş., \& Kuru, O. (2017). An evaluation of factors affecting decision making among 4 th grade elementary school students with low socio-economic status. International Electronic Journal of Elementary Education, 9(4), 787-808.

Lachance, J. A., \& Mazzocco, M. M. M. (2006). A longitudinal analysis of sex differences in math and spatial skills in primary school age children. Learning and Individual Differences, 16(3), 195-216.

LeFevre, J.-A., Skwarchuk, S.-L., Smith-Chant, B. L., Fast, L., Kamawar, D., \& Bisanz, J. (2009). Home numeracy experiences and children's math performance in the early school years. Canadian Journal of Behavioural Sciences, 41(2), 55-66.

Lindberg, S. M., Hyde, J. S., Petersen, J. L., \& Linn, M. C. (2010). New trends in gender and mathematics performance: A meta-analysis. Psychological Bulletin, 136(6), 1123-1135.

Marshall, S. P., \& Smith, J. D. (1987). Sex differences in learning mathematics: A longitudinal study with item and error analyses. Journal of Educational Psy- 
chology, 79(4), 372-383.

Mazzocco, M. M. M., \& Räsänen, P. (2013). Contributions of longitudinal studies to evolving definitions and knowledge of developmental dyscalculia. Trends in Neuroscience and Education, 2(2), 65-73.

Mazzocco, M. M. M. (2007). Defining and differentiating mathematical learning disabilities and difficulties. In D. B. Berch \& M. M. M. Mazzocco (Eds.), Why is math so hard for some children: The nature and origins of mathematical learning difficulties and disabilities (pp. 29-47). Baltimore, MD: Brookes Publishing.

Mazzocco, M. M. M., \& Myers, G. F. (2003). Complexities in identifying and defining mathematics learning disability in the primary school-age years. Annals of Dyslexia, 53(1), 218-253.

McCloskey, M. (2007). Quantitative literacy and developmental dyscalculias. In D. B. Berch \& M. M. M. Mazzocco (Eds.), Why is math so hard for some children: The nature and origins of mathematical learning difficulties and disabilities (pp. 29-47). Baltimore, MD: Brookes Publishing.

McNamara, D., \& Kendeou, P. (2011). Translating advances in reading comprehension research to educational practice. International Electronic Journal of Elementary Education, 4(1), 33-46.

Morgan, P. L., Farkas, G., \& Wu Qiong (2009). Five-year growth trajectories of kindergarten children with learning difficulties in mathematics. Journal of Learning Disabilities, 42(4), 306-321.

Mullis, I. V. S., Martin, M. O., Foy, P., \& Arora, A. (2012). TIMSS 2011 international results in mathematics. Chestnut Hill, MA: TIMSS \& PIRLS International Study Center, Lynch School of Education, Boston College. Retrieved from https://timssandpirls. bc.edu/timss2011/downloads/T11_IR_Mathematics_FullBook.pdf

Murphy, M. M., Mazzocco, M. M. M., Hanich, L. B., \& Early, M. C. (2007). Cognitive characteristics of children with mathematics learning disability (MLD) vary as a function of the cutoff criterion used to define MLD. Journal of Learning Disabilities, 40(5), 458-478.

Ostad, S. A. (1998). Developmental differences in solving simple arithmetic word problems and simple number-fact problems: A comparison of mathematically normal and mathematically disabled children. Mathematical Cognition, 4(1), 1-19.

Patton, J. R., Cronin, M. E., Bassett, D. S., \& Koppel, A. E. (1997). A life skills approach to mathematics instruction: Preparing students with learning disabilities for the real-life math demands of adulthood. Journal of Learning Disabilities, 30(2), 178-187.

Raven, J. C. (1976). Standard progressive matrices: Sets $A, B$, $C, D \& E$. Oxford: Oxford Psychologists Press.

Raven, J., Raven, J. C., \& Court, J. H. (1998). Manual for standard progressive matrices: Including the parallel and plus versions. San Antonio, TX: Harcourt.

Reid, M., \& Reid, S. (2017). Learning to be a math teacher: What knowledge is essential? International
Electronic Journal of Elementary Education, 9(4), 851-872.

Räsänen, P., Linnanmäki, K., Haapamäki, C., \& Skagersten, D. (2008). RMAT - Test av räknefärdighet hos evelver $i$ åldern 9-12 år. [A mathematical achievement test for ages 9-12 in Finnish-Swedish]. Jyväskylä: Niilo Mäki Institute.

Räsänen, P., \& Salihu, L. (2006). RMAT - Test i arritshmërisë në matematikë për moshën 9-12 vjeçare. [A mathematical achievement test for 9-12-year-olds]. Jyväskylä: Niilo Mäki Institute.

Räsänen, P. (2004). RMAT (laskutaidon testi 9-12 -vuotiaille: Kasikirja). [A mathematical achievement test for 9-12-year-olds: Manual]. Jyväskylä: Niilo Mäki Institute.

Räsänen, P., \& Ahonen, T. (1995). Arithmetic disabilities with and without reading difficulties: A comparison of arithmetic errors. Developmental Neuropsychology, 11(3), 275-295.

Reid, M., \& Reid, S. (2017). Learning to be a math teacher: What knowledge is essential? International Electronic Journal of Elementary Education, 9(4), 851-872

Rittle-Johnson, B., Siegler, R. S., \& Alibali, M. W. (2001). Developing conceptual understanding and conceptual skills in mathematics: An iterative process. Journal of Educational Psychology, 93(2), 346-362.

Royer, J. M., \& Walles, R. (2007). Influences of gender, ethnicity, and motivation on mathematical performance. In D. B. Berch \& M. M. M. Mazzocco (Eds.), Why is math so hard for some children: The nature and origins of mathematical learning difficulties and disabilities (pp. 349-367). Baltimore, MD: Brookes Publishing.

Salihu, L., Aro, M., \& Räsänen, P. (2017). Dynamic potential of feedback in self-regulated learning and motivation of children with mathematical learning difficulties. Hrvatska Revija za Rehabilitacijska Istraživanja, 53(2), 111-129.

Salihu, L. (2008). Test i performancës në matematikë - Kalkulimet (TPM-K). [Mathematics performance test on calculations, MPT-C]. (Unpublished test material). University of Prishtina, Kosovo.

Siegler, R. S. (2007). Foreword: The birth of a new discipline. In D. B. Berch \& M. M. M. Mazzocco (Eds.), Why is math so hard for some children: The nature and origins of mathematical learning difficulties and disabilities (pp. xvii-xxii). Baltimore, MD: Brookes Publishing.

Sirin, S. R. (2005). Socioeconomic status and academic achievement: A meta-analytic review of research 1990-2000. Review of Educational Research, 75(3), 417-445.

Stock, P., Desoete, A., \& Roeyers, H. (2010). Detecting children with arithmetic disabilities from kindergarten: Evidence from a 3-year longitudinal study on the role of preparatory arithmetic abilities. Journal of Learning Disabilities, 43(3), 250-268.

Swanson, H. L., \& Beebe-Frankenberger, M. (2004). The relationship between working memory and math- 
ematical problem solving in children at risk and not at risk for serious math difficulties. Journal of Educational Psychology, 96(3), 471-491.

Tarrou, A.-L. H. (1996). Changes in teacher's role as a reflection of changes in society. In B. Kotschy (Ed.), Teacher's role and teacher education: A Central-East European view (pp. 11-19). Budapest, Hungary: ATEE Cahier, 10.

Tate, W. F. (1997). Race-ethnicity, SES, gender, and language proficiency trends in mathematics achievement: An update. Journal for Research in Mathematics Education, 28(6), 652-679.

Thomas, G. (2013). A review of thinking and research about inclusive education policy, with suggestions for a new kind of inclusive thinking. British Educational Research Journal, 39(3), 473-490.

Thornton, F. (2018). Counselors and special educators in rural schools working together to create a positive school community. International Electronic Journal of Elementary Education, 10(3), 385-389.

Vukovic, R. K., \& Siegel, L.S. (2010). Academic and cognitive characteristics of persistent mathematics difficulty form first through fourth grade. Learning Disabilities Research \& Practice, 25(1), 25-38. 